\title{
Testing the Beneficial Acclimation Hypothesis and Its Alternatives for Locomotor Performance
}

\author{
Jacques A. Deere ${ }^{\star}$ and Steven L. Chown ${ }^{\dagger}$
}

Centre for Invasion Biology, Department of Botany and Zoology, Stellenbosch University, Private Bag X1, Matieland 7602, South Africa

Submitted August 12, 2005; Accepted June 26, 2006;

Electronically published October 5, 2006

Online enhancements: appendixes. responses of individuals to changing temperatures, water availability, and resource conditions (reviews in Prosser 1986; Hochachka and Somero 2002; Chown and Nicolson 2004). Nonetheless, this beneficial acclimation hypothesis (BAH; Leroi et al. 1994) has in recent years received vigorous criticism from several perspectives. These include the failure of many studies to include a priori the wide range of alternative hypotheses for the responses of individuals to a changing environment (Huey and Berrigan 1996; Huey et al. 1999) and the generally poor empirical support for the BAH in tests that have examined the hypothesis explicitly (Leroi et al. 1994; Zamudio et al. 1995; Bennett and Lenski 1997; Sibly et al. 1997; Woods 1999; Gibert et al. 2001; Gilchrist and Huey 2001; Woods and Harrison 2001). Thus, much of the recent literature suggests that, despite the seemingly obvious benefits of acclimation (or acclimatization), little support exists for this idea. Many of the alternative hypotheses, such as optimal developmental temperatures (Cohet and David 1977; Huey and Berrigan 1996), now appear more plausible.

Given the wide range of scenarios under which adaptive phenotypic plasticity is likely to evolve (Scheiner 1993; Agrawal 2001; Berrigan and Scheiner 2004), the lack of support for the BAH is counterintuitive, at least from a physiological perspective. Indeed, several authors take issue with many of the explicit tests of the BAH. Echoing earlier distinctions between labile and fixed traits (Scheiner 1993), Wilson and Franklin (2002b) argued that the majority of thermal acclimation tests of the $\mathrm{BAH}$ are neither direct nor complete because they assess the adaptive significance of developmental plasticity rather than investigating what comparative physiologists regard as acclimation (or acclimatization; e.g., Spicer and Gaston 1999, pp. 32-38; Willmer et al. 1999, pp. 9-12). That is, many past assessments of phenotypic plasticity have involved alteration of rearing regimes and subsequent assessment of adults rather than assessment of changes of phenotype within a given life stage. According to Wilson and Franklin $(2002 b)$, acclimation responses are reversible, facultative changes to the phenotype, while developmental plasticity concerns those phenotypic alterations made as a conse-

Am. Nat. 2006. Vol. 168, pp. 630-644. (C) 2006 by The University of Chicago 0003-0147/2006/16805-41239\$15.00. All rights reserved. 
quence of different developmental environments. While the extent to which developmental changes are nonreversible for physiological traits (as opposed to body size in organisms with determinate growth) is not well established (see Fischer et al. 2003; Zeilstra and Fischer 2005 for contrary examples), the distinction remains valid. Woods and Harrison (2002) offered a different perspective, arguing that most explicit tests of the BAH compare animals in optimal environments with those under stressful conditions. Long-term exposure to the latter is likely to impair organismal performance in all other environments, thus compromising some tests of the $\mathrm{BAH}$. In addition, Woods and Harrison (2002) suggested that tests of the $\mathrm{BAH}$ should focus on fitness consequences of individual traits and not on the entire suite of characters that constitute fitness. Failure to do so apparently has obscured the relationship between fitness and acclimation.

Both Woods and Harrison (2002) and Wilson and Franklin (2002b) made several suggestions for ways in which tests of the BAH might be improved, especially for investigations of phenotypic plasticity within a given life stage. In essence, they proposed that the rigorous, strong inference approach adopted in analyses of developmental plasticity (e.g., Huey et al. 1999) should be used, that the range of environments investigated should perhaps not include those that impose considerable stress (but see also Hoffmann 1995; Loeschcke and Hoffmann 2002), and that a focus on individual traits is required. Clearly, aspects of the explicit critiques of previous, development-based tests of the BAH are controversial. However, implementation of the above recommendations could go some way toward resolving the surprising mismatch between what comparative physiologists consider to be self-evident (acclimation is beneficial) and what tests of the idea have indicated to date.

Here, we implement these recommendations and assess the plasticity of the temperature sensitivity of locomotor speed in five closely related species of oribatid mite. These species occur over a range of environments from strictly marine to terrestrial at sub-Antarctic Marion Island. Locomotor speed was chosen as a trait because it is a convenient measure of physiological performance in oribatid mites (Marshall and Chown 1995; Marshall et al. 1995) and is directly linked to fitness in a wide variety of organisms (Huey and Stevenson 1979; Gilchrist 1996; Gibert et al. 2001; but see also Angilletta et al. 2002 for exceptions). Mites were chosen because their small size (Mercer et al. 2001) means thermoconformation (Stevenson 1985), making them ideal for examining environmental sensitivity in physiological traits (Gilchrist 1996).

Acclimation effects on the responses of three aspects of thermal performance curves were examined: maximum speed $\left(u_{\max }\right)$, temperature of the maximum speed $(\approx$ op- timum temperature, $\left.T_{\text {opt }}\right)$, and performance breadth $\left(T_{\mathrm{br}}\right.$; Huey and Stevenson 1979; Gilchrist 1996). Although a variety of predictions have been made about the shape and position of performance curves for various acclimation hypotheses, particularly for $u_{\max }$ and $T_{\mathrm{opt}}$ and their covariation, we revisited these a priori predictions because, in some instances, it is clear that several quite similar predictions can be made for the different hypotheses. For example, Gilchrist (1996) suggested that the "hotter-isbetter" hypothesis predicts a positive relationship between optimum temperature and maximum velocity (see also Carrière and Boivin 1997). However, a positive relationship between these variables, over a range of acclimation temperatures, can arise in two different ways. Thus, our predictions for the position $\left(T_{\mathrm{opt}}\right.$ and $\left.u_{\mathrm{max}}\right)$ and shape $\left(T_{\mathrm{br}}\right)$ of the performance curves for the various acclimation hypotheses are as follows.

The BAH is defined as follows: "acclimation to a particular environment gives an organism a performance advantage in that environment over another organism that has not had the opportunity to acclimate to that particular environment" (Leroi et al. 1994, p. 1917). Therefore, it typically predicts covariation in $T_{\text {opt }}$ and $u_{\max }$ and some overlap of the performance curves (fig. 1; see also Huey et al. 1999). However, the BAH can also be interpreted to mean that there is no relationship between $T_{\text {opt }}$ and $u_{\max }$. This is complete temperature compensation (i.e., the maintenance of rate in the face of temperature changes; Clarke 2003), which is clearly a special case of beneficial acclimation (fig. 1). Partial compensation, as is apparently common for many organisms (Clarke 2003), can likewise be interpreted as a special case of beneficial acclimation. "Colder is better" (CIB) predicts that an organism acclimated to a low-temperature environment will always have a performance advantage over another organism held at a warmer environment (fig. 1). "Hotter is better" (HIB) predicts the opposite (fig. 1). In its simplest form, "inverse acclimation" is similar to the inverse compensation that has occasionally been documented in investigations of acclimation effects on metabolic rate (Huey and Berrigan 1996; fig. 1). The deleterious acclimation hypothesis (DAH; Loeschcke and Hoffmann 2002; Wilson and Franklin 2002a; Woods and Harrison 2002) predicts a substantial decline in performance for organisms held at extreme temperatures relative to those held at intermediate temperatures or those that typically do not experience such extremes in the field (fig. 1). To some extent, this hypothesis is similar to the optimal acclimation (originally optimal developmental) temperature hypothesis (Cohet and David 1977; Huey et al. 1999). Finally, the performance curves might not change in response to acclimation, revealing no variation in $T_{\text {opt }}$ and $u_{\max }$ and no covariation between them. Such a lack of response to acclimation would indicate no 

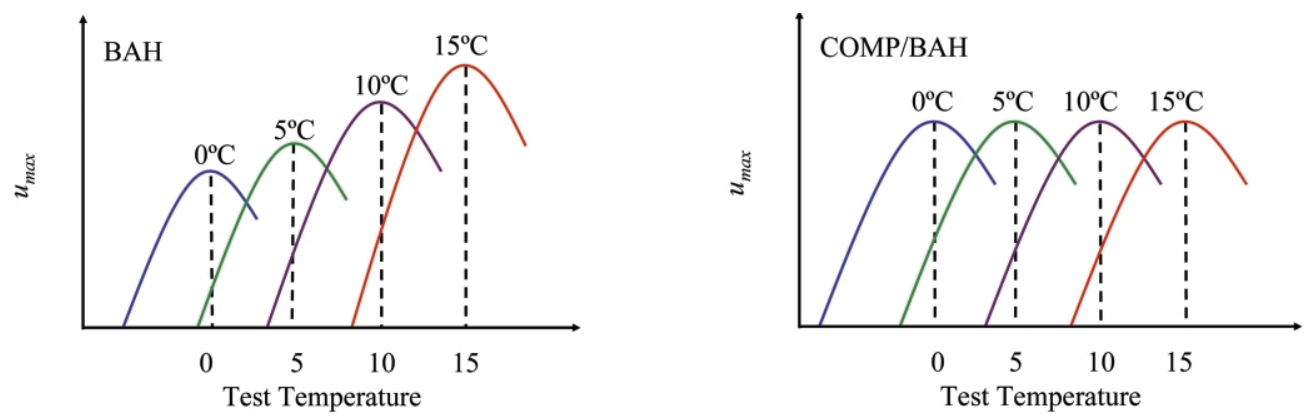

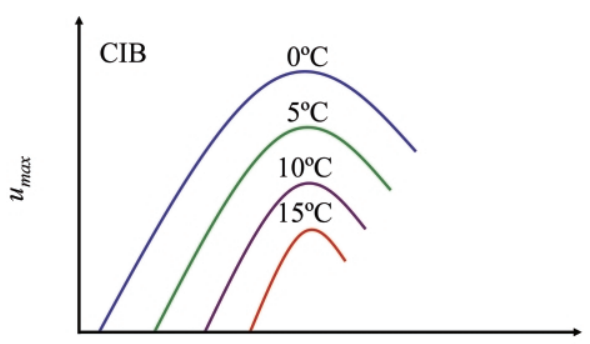

Test Temperature
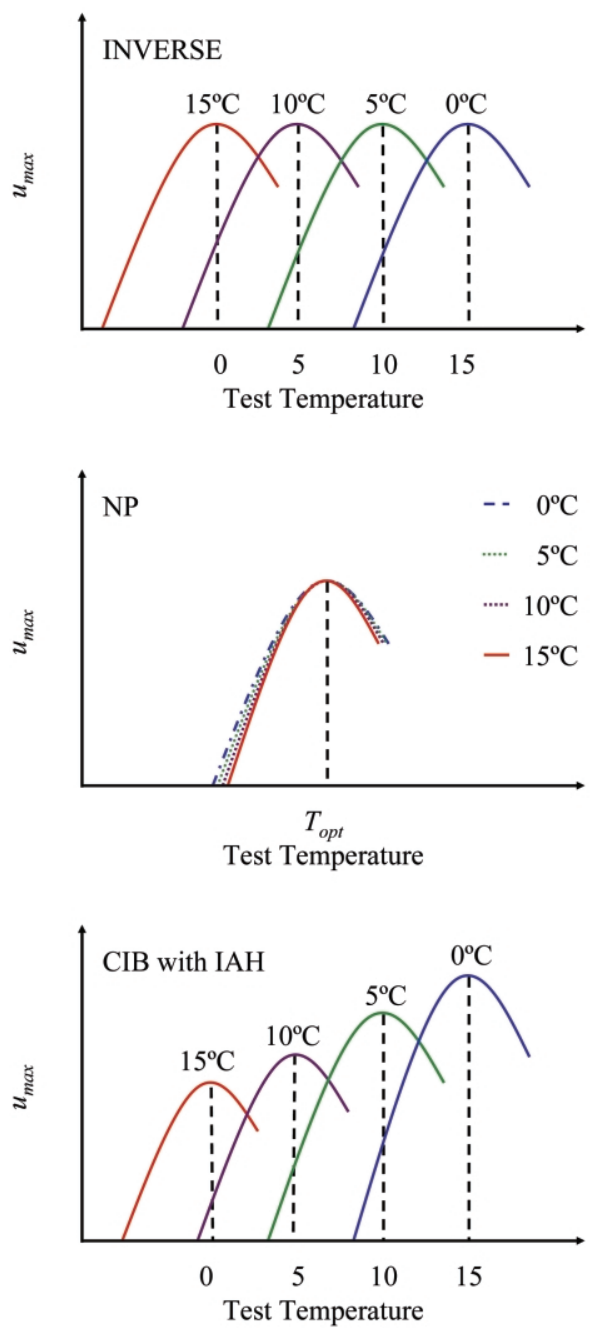

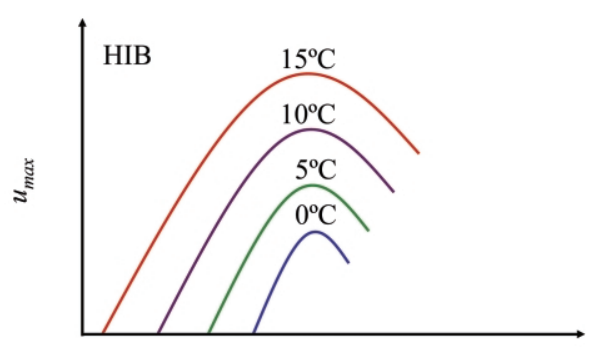

Test Temperature
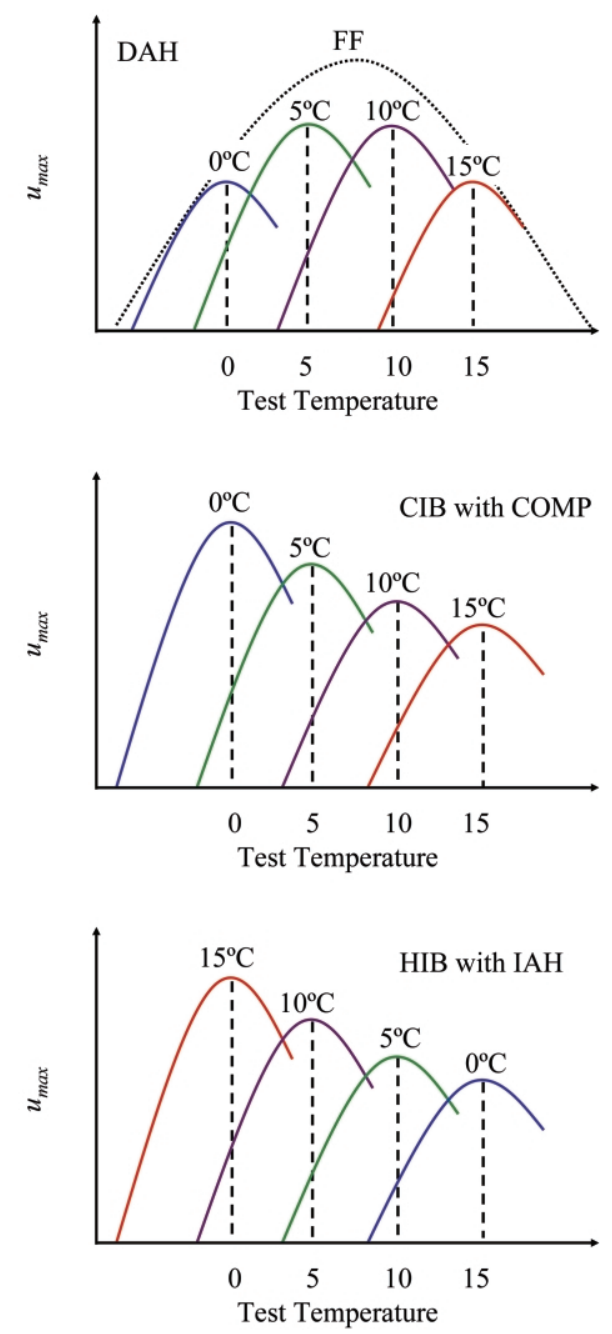
plasticity (fig. 1). An absence of phenotypic plasticity, which in some circumstances can be considered adaptive (Tufto 2000), has been predicted in models of the response of traits to environments where environmental cues are misleading or costs of plasticity are high (Moran 1992; Van Tienderen 1997; Kingsolver and Huey 1998; Tufto 2000; Sultan and Spencer 2002; Berrigan and Scheiner 2004).

When assessing the alternative acclimation hypotheses on the basis of performance curves, it is not only the values of $T_{\text {opt }}$ and $u_{\max }$ that are significant for each acclimation treatment but also their covariation, or the positions of the curves relative to each other (see also Gilchrist and Huey 2004). Indeed, the hypotheses typically discussed as exclusive alternatives represent points along a continuum of variation in the position of performance curves (see also Huey et al. 1999; fig. 1). Thus, the performance curves that are the outcome of a combination of CIB and compensation take a form very different from those that are the outcome of CIB and inverse acclimation or of HIB and inverse acclimation (fig. 1). Nonetheless, it is clear that the positions of the curves can take a wide variety of forms and not just those illustrated in figure 1.

How acclimation-related changes in $T_{\mathrm{br}}$ relate to this variation and could potentially be used to assess the various acclimation hypotheses is more difficult to determine. The $T_{\mathrm{br}}$ could, under some circumstances, be used to distinguish the DAH from the optimal acclimation temperature hypothesis and might also be expected to change most significantly in organisms exposed to fluctuating, as opposed to constant, temperatures (Huey and Kingsolver 1993; Kingsolver and Huey 1998; Huey et al. 1999). However, if an organism has a consistent advantage after acclimation to either a low temperature (i.e., CIB) or a high temperature (HIB), it might be expected under certain circumstances that a consistent trend in $T_{\mathrm{br}}$ would be found from high to low acclimation temperature, or vice versa, respectively. However, such effects are likely to be dependent on the extent and nature of the trade-off between $T_{\mathrm{br}}$ and $u_{\max }$ (Huey and Hertz 1984; Gilchrist 1996; Angilletta et al. 2002).

\section{Methods \\ Study Site and Animals}

Specimens were collected from April 2002 to April 2003 on the east coast of sub-Antarctic Marion Island ( $46^{\circ} 54^{\prime} \mathrm{S}$, $37^{\circ} 45^{\prime} \mathrm{E}$ ), a small, isolated volcanic island in the Southern Ocean. The island has a low mean annual air temperature (ca. $5.7^{\circ} \mathrm{C}$ ), high humidity $(83 \%)$, and an evenly distributed annual precipitation of ca. 1,900 mm (Smith 2002). It is typically cloudy, with strong, predominantly westerly winds that reach gale force throughout much of the year (Schulze 1971). Although climatic (especially temperature) variation is lower than at many other sites, this variation is unpredictable on a variety of temporal scales, especially at low altitudes, because of the regular passage of fronts over the island (Schulze 1971; Smith 2002).

Five ameronothroid mite species were studied. Halozetes marinus and Halozetes marionensis are found in the littoral zones along the rocky shores, and the former species is strictly marine. Halozetes belgicae is found in rocky supralittoral zones, while Halozetes fulvus and Podacarus auberti are terrestrial and occupy a wide range of habitats (Mercer et al. 2000; Barendse et al. 2002). For all species (except $H$. marionensis, which was collected in situ from the rocky substrate and transferred into moistened, plaster of parislined vials), the vegetation on which the mite species occurred was collected and brought back to the laboratory, and animals were extracted by hand. Animals were randomly assigned to five groups of 20-40 individuals each. The performance of individuals in one group was assessed immediately (within $24 \mathrm{~h}$, labeled "field-fresh"). The reason we used this group was to determine whether acclimation might have been generally stressful. In this case, significant differences between performance curves of individuals from one or more acclimation treatments and those of individuals taken directly from the field might be expected. Each of the remaining groups was placed in a large vial containing a moistened plaster of paris substrate, provided with food and water (typically lichens and algae), assigned to one of four acclimation temperatures $\left(0^{\circ}, 5^{\circ}, 10^{\circ}\right.$, and $15^{\circ} \mathrm{C}, \pm 1^{\circ} \mathrm{C}$ in each case), and held there for 7 days (for rationale, see Hoffmann and Watson 1993; Klok and Chown 2003; Ter-

Figure 1: Predictions from each of the major hypotheses for the response of individual performance curves to acclimation. In each case, four acclimation temperatures from low to high are indicated (as an example, we use $0^{\circ}-15^{\circ} \mathrm{C}$ in $5^{\circ}$ increments: $0^{\circ} \mathrm{C}[$ blue $], 5^{\circ} \mathrm{C}[$ green $], 10^{\circ} \mathrm{C}[$ purple], and $\left.15^{\circ} \mathrm{C}[\mathrm{red}]\right)$, and in one case the expectation for field-fresh (FF) individuals is also shown. BAH $=$ beneficial acclimation hypothesis, $\mathrm{COMP} / \mathrm{BAH}=$ complete temperature compensation (an instance of $\mathrm{BAH}$ ), $\mathrm{CIB}=$ colder is better, HIB $=$ hotter is better, $\mathrm{IAH}=$ inverse acclimation hypothesis, $\mathrm{DAH}=$ deleterious acclimation hypothesis, $\mathrm{NP}=$ no plasticity, $\mathrm{CIB}$ with COMP = combination of colder is better and compensation, $\mathrm{CIB}$ with IAH = combination of colder is better and inverse acclimation, and HIB with IAH = combination of hotter is better and inverse acclimation. Several of these examples represent extremes of the variation that could be found in the relative positions of the performance curves for each of the hypotheses, although, clearly, much variation could potentially be found in the positions of the curves. 
blanche et al. 2006). The acclimation temperatures were based on terrestrial microclimate temperatures, which vary from a mean of approximately $0^{\circ} \mathrm{C}$ in winter to $12^{\circ} \mathrm{C}$ in summer, depending on the habitat (Chown and Crafford 1992; Blake 1996; table 1). The $15^{\circ} \mathrm{C}$ acclimation treatment was high, though not outside terrestrial microhabitat temperatures measured at the island (Chown and Crafford 1992; table 1). Day length was set to $14 \mathrm{~L}: 10 \mathrm{D}$ for the $10^{\circ}$ and $15^{\circ} \mathrm{C}$ acclimation treatments and to $9 \mathrm{~L}: 15 \mathrm{D}$ for the $0^{\circ}$ and $5^{\circ} \mathrm{C}$ acclimation treatments. Because the mites are small, the tubes within which they were held occupied little space on a single shelf, and therefore shelf effects in the climate chambers are unlikely to have had any influence on the temperature at which the individuals were held. Moreover, the same small areas in the climate chambers were used for each species.

\section{Locomotion Trials}

Individual mites were observed on a temperaturecontrolled stage using a stereo microscope $(x 16$ magnification). To induce walking, mites were exposed to a cold light source, and the frequency of movements of the front right leg was counted for each mite over a range of temperatures (Marshall et al. 1995). Typically, eight to 10 temperatures at $5^{\circ} \mathrm{C}$ intervals $\left(-10^{\circ}\right.$ to $\left.35^{\circ} \mathrm{C}\right)$ were used. Mites were assessed in a pseudorandom design that used nonstressful $\left(0^{\circ}-30^{\circ} \mathrm{C}\right)$ temperatures first and then concluded with the lowest and highest temperatures. In the latter case, mites were returned to their acclimation temperature for 1-2 $\mathrm{h}$ while the experimental setup equilibrated to the final, highest temperature. The species all have lower lethal temperatures less than $-10^{\circ}$ to $-6^{\circ} \mathrm{C}$ and upper lethal temperatures greater than $35^{\circ} \mathrm{C}$ (Deere et al. 2006), which resulted in the extreme assessment temperatures being varied slightly between species. The lower assessment temperatures seemed to have no stressful long-term effects on individuals investigated in pilot trials. The number of leg strokes was counted over a 20 -s period but only after 20 $s$ had elapsed once the mite had started walking. Counts were abandoned if mites faltered. To determine whether the data were representative of the capabilities of each animal, the number of leg strokes per $20 \mathrm{~s}$ was counted three times for each assessment temperature to provide a short-term assessment of the reliability of the counts. A sample size of 20 animals was used per acclimation temperature, but the same individuals were used at each temperature for a given species and acclimation trial. These locomotion data were used to construct performance curves (Gilchrist 1996; fig. 2), of which the key traits are $T_{\text {opt }}$, the thermal condition that maximizes performance, or the optimum temperature; $u_{\max }$, the maximum rate of performance, or maximum speed (although we note that stroke interval and maximum speed are not identical unless it is presumed that stride length does not vary with stride frequency); and $T_{\mathrm{br}}$, the index of the breadth of the curve, or performance breadth. Values of $T_{\text {opt }}$ and $u_{\max }$ were obtained from the experimental data and were used to calculate $T_{\text {br }}$ using Gilchrist's (1996) formula:

$$
T_{\mathrm{br}}=\sqrt{\sum\left[\frac{u_{i}\left(T_{i}-T_{\mathrm{opt}}\right)}{u_{\max }}\right]^{2}},
$$

where $T_{\text {opt }}$ is the temperature at which an individual had the most leg strokes per $20 \mathrm{~s}, u_{\max }$ is the number of leg strokes per $20 \mathrm{~s}$ at $T_{\mathrm{opt}}$, and $u_{i}$ is number of leg strokes per $20 \mathrm{~s}$ at temperature $T_{i}$. Because each individual was assessed over the full range of temperatures, three performance curves were constructed for each individual.

The traits investigated here are in many ways similar to those that have been developed for reaction norms (David et al. 1997). However, unlike some authors, we do not consider the acute effects of temperature on performance to be similar to the effects of acclimation but rather prefer to draw a distinction between the two (see also Huey and

Table 1: Sea surface (SS) temperature and microhabitat temperature $\left({ }^{\circ} \mathrm{C}\right)$ of two terrestrial sites ( 0 and $200 \mathrm{~m}$ above sea level) for 2 years at Marion Island

\begin{tabular}{lcccccc}
\hline Site, year & Mean & Abs min & Abs max & Mean min & Mean max & Range \\
\hline SS: & & & & & & \\
2002 & 5.4 & 3.7 & 8.5 & 4.9 & 6.2 & 4.8 \\
2003 & 5.4 & 3.7 & 8 & 4.7 & 6.0 & 4.3 \\
0 m: & & & & & & \\
2002 & 5.3 & .5 & 22.5 & 3.8 & 7.1 & 22.0 \\
2003 & 7.0 & 1 & 22 & 5.1 & 8.6 & 21.0 \\
$200 \mathrm{m:}$ & & & & & & \\
2002 & 4.4 & -5.0 & 18.5 & 2.2 & 7.0 & 23.5 \\
2003 & 5.2 & -6.0 & 19 & 3.5 & 6.6 & 25 \\
\hline
\end{tabular}

Note: Mean, mean minimum (Mean min), mean maximum (Mean max), absolute minimum (Abs $\min$ ), and absolute maximum (Abs max) temperatures and the temperature range are shown. 
Littoral and Supra-littoral
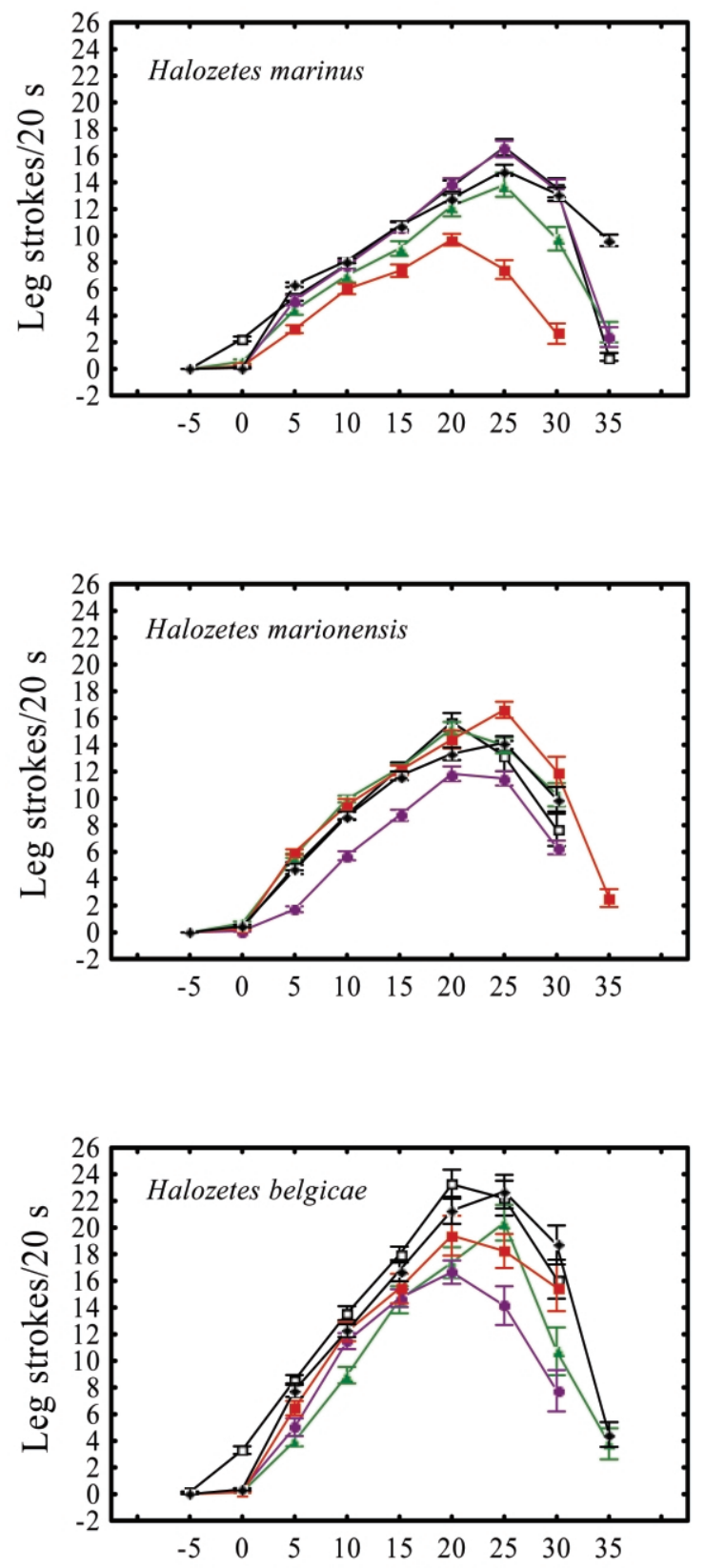

Terrestrial
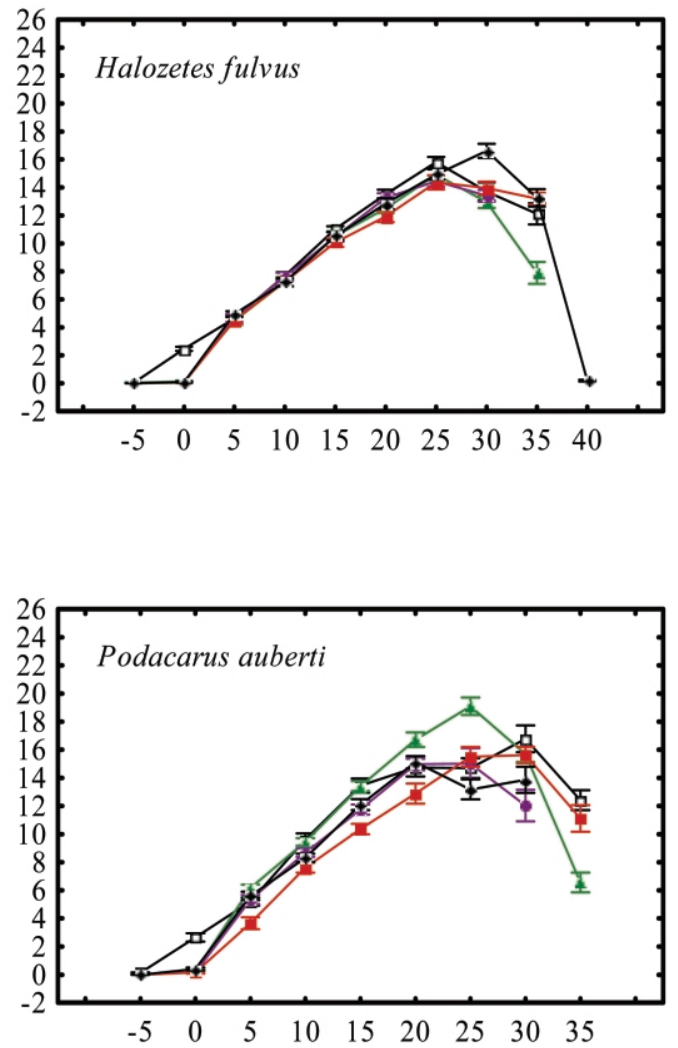

Test Temperature $\left({ }^{\circ} \mathrm{C}\right)$

Figure 2: Performance curves for four experimental acclimation groups $-0^{\circ} \mathrm{C}$ (black squares), $5^{\circ} \mathrm{C}$ (green triangles), $10^{\circ} \mathrm{C}$ (purple circles), and $15^{\circ} \mathrm{C}$ (red squares)—and for field-fresh individuals (black diamonds) for Halozetes marinus, Halozetes marionensis, Halozetes belgicae, Halozetes fulvus, and Podacarus auberti. 
Berrigan 1996). In other words, we are interested in the effects of acclimation on the key traits that can be derived from the performance curve. Thus, we do not call the performance curve a reaction norm (as Angilletta et al. [2003] do).

\section{Data Analysis}

On the basis of the repeated counts, three performance curves were constructed for each individual at each acclimation temperature, and repeatability of each of the key traits derived from the performance curve was assessed using the intraclass correlation coefficient (Lessells and Boag 1987; Falconer and Mackay 1996). The effects of the acclimation treatments on each of the traits $\left(T_{\mathrm{opt}}, u_{\mathrm{max}}\right.$, and $T_{\mathrm{br}}$ ) in each of the species were assessed initially by plotting the performance curves and by formally examining the effects of the acclimation temperatures on the traits with a generalized linear model (GLZ). For optimum temperature and performance breadth, a GLZ assuming a normal distribution of errors with a log link function was used (these models gave the best fit based on deviance/df), while maximum speed (which represents count data) was analyzed using a GLZ assuming a Poisson distribution of errors with a log link function.

A formal test of the alternative hypotheses was undertaken using ordered-factor ANOVAs with single-degreeof-freedom orthogonal polynomial contrasts, as recommended by Huey et al. (1999) and implemented in R (http://www.r-project.org/). In keeping with the strong inference approach and the necessity of examining covariation of $T_{\text {opt }}$ and $u_{\text {max }}$, predictions were made for the significance and sign of the linear and quadratic terms for $T_{\text {opt }}$ and $u_{\text {max }}$ for each of the alternative hypotheses (fig. 1; table 2). In many instances, no predictions were made by the alternative hypotheses for quadratic contrasts and certainly none for cubic contrasts, and in these instances contrasts were not given further consideration. In the case of the deleterious acclimation hypothesis, animals might have been exposed to stress-inducing temperatures at either or both ends of the spectrum of acclimation treatments, meaning that the linear term could be either negative or positive. For $T_{b r}$, predictions of the sign and significance of the contrasts were more difficult to make, except in the case of no plasticity (see discussion above). The ordered-factor approach requires strict adherence to the assumptions of ANOVA, a balanced design, normally distributed residuals, and homogeneity of variances within cells (Huey et al. 1999). These conditions were typically met. Furthermore, an initial analysis (data not shown) indicated pervasive interactions between the species and acclimation treatment contrasts. Therefore, each species was analyzed separately.
Table 2: Predictions of the significance and sign of the linear and quadratic effects of acclimation temperature on optimum temperature $\left(T_{\mathrm{opt}}\right)$, maximum rate of performance $\left(u_{\max }\right)$, and performance breadth $\left(T_{\mathrm{br}}\right)$ for each of the alternative acclimation hypotheses and combinations thereof illustrated in figure 1

\begin{tabular}{|c|c|c|c|}
\hline Hypothesis & $T_{\mathrm{opt}}$ & $u_{\max }$ & $T_{\mathrm{br}}$ \\
\hline Beneficial acclimation & $\mathrm{L}^{+}$ & $\mathrm{L}^{+}$ & \\
\hline $\begin{array}{l}\text { Compensation/beneficial } \\
\text { acclimation }\end{array}$ & $\mathrm{L}^{+}$ & NS & \\
\hline Colder is better & NS & $\mathrm{L}^{-}$ & $\mathrm{L}^{-}$ \\
\hline Hotter is better & NS & $\mathrm{L}^{+}$ & $\mathrm{L}^{+}$ \\
\hline Inverse acclimation & $\mathrm{L}^{-}$ & NS & \\
\hline Deleterious acclimation & $\mathrm{L}^{+/-}, \mathrm{Q}^{-}$ & $\mathrm{L}^{+/-}, \mathrm{Q}^{-}$ & \\
\hline No plasticity & NS & NS & NS \\
\hline $\begin{array}{l}\text { Colder is better with } \\
\text { compensation }\end{array}$ & $\mathrm{L}^{+}$ & $\mathrm{L}^{-}$ & \\
\hline $\begin{array}{l}\text { Colder is better with inverse } \\
\text { acclimation }\end{array}$ & $\mathrm{L}^{-}$ & $\mathrm{L}^{-}$ & \\
\hline $\begin{array}{l}\text { Hotter is better with inverse } \\
\text { acclimation }\end{array}$ & $\mathrm{L}^{-}$ & $\mathrm{L}^{+}$ & \\
\hline
\end{tabular}

Note: $\mathrm{L}^{+}=$positive linear, $\mathrm{L}^{-}=$negative linear, $\mathrm{Q}^{-}=$negative quadratic, and NS = not significant.

\section{Results}

Repeatability was generally higher for $u_{\max }$ than for $T_{\mathrm{opt}}$ and $T_{\mathrm{br}}$ in all of the species across all of the acclimation temperatures, and low repeatability values were occasionally found for $T_{\mathrm{br}}$ and $T_{\mathrm{opt}}$, especially in those individuals acclimated to $0^{\circ}$ and $5^{\circ} \mathrm{C}$ (app. A in the online edition of the American Naturalist). Nonetheless, performance was generally consistent within individuals, and the counts provided a reasonably accurate estimate of that performance. The statistical analyses, as described above, were therefore based on the mean values of the three counts for each individual at each assessment temperature.

In the case of maximum speed $\left(u_{\max }\right)$ and performance breadth $\left(T_{\mathrm{br}}\right)$, no consistent differences were generally associated with acclimation temperature for any of the species (fig. 2; table 3). Moreover, the values of the traits in the acclimation groups did not differ either significantly or substantially from the values obtained from the fieldfresh group of individuals. Rather, trait values appeared to be similar across the acclimation temperatures. The only exception was $u_{\max }$ in Halozetes marinus, which tended to decline with temperature (but only at $15^{\circ} \mathrm{C}$; fig. 2). Optimum temperature showed very much the same pattern of little variation associated with acclimation temperature and no substantial or consistent differences from fieldfresh values. The sole exception was found in H. marinus, where $T_{\text {opt }}$ declined significantly at the highest acclimation temperature (fig. 2).

The ordered-factor approach revealed support for three 
Table 3: Mean \pm SE for maximum speed $\left(u_{\max }\right)$, optimum temperature $\left(T_{\mathrm{opt}}\right)$, and performance breadth $\left(T_{\mathrm{br}}\right)$ for each of the species of Halozetes and for Podacarus auberti

\begin{tabular}{|c|c|c|c|c|c|c|}
\hline Trait, species & Field-fresh & $0^{\circ} \mathrm{C}$ & $5^{\circ} \mathrm{C}$ & $10^{\circ} \mathrm{C}$ & $15^{\circ} \mathrm{C}$ & $\overline{\chi^{2}(\mathrm{df}=4)}$ \\
\hline \multicolumn{7}{|c|}{$u_{\max }($ leg strokes $/ 20 \mathrm{~s}):$} \\
\hline H. marinus & $14.9 \pm .5^{\mathrm{A}}$ & $16.6 \pm .6^{\mathrm{A}}$ & $14.1 \pm .8^{\mathrm{A}}$ & $16.1 \pm .7^{\mathrm{A}}$ & $9.3 \pm .6^{\mathrm{B}}$ & $44.6^{* * *}$ \\
\hline H. marionensis & $14.7 \pm .5^{\mathrm{AB}}$ & $16.1 \pm .7^{\mathrm{A}}$ & $15.6 \pm .5^{\mathrm{A}}$ & $12.6 \pm .5^{\mathrm{B}}$ & $16.8 \pm .6^{\mathrm{A}}$ & $13.6^{* \star}$ \\
\hline H. belgicae & $24.4 \pm .7^{\mathrm{A}}$ & $23.7 \pm 1.2^{\mathrm{AB}}$ & $21.4 \pm 1.3^{\mathrm{ABC}}$ & $17.4 \pm 1.0^{\mathrm{C}}$ & $19.9 \pm 1.3^{\mathrm{BC}}$ & $29.3^{\star * *}$ \\
\hline H. fulvus & $16.8 \pm .5$ & $16.2 \pm .4$ & $15.0 \pm .4$ & $14.9 \pm .3$ & $15.1 \pm .5$ & $3.7 \mathrm{NS}$ \\
\hline P. auberti & $16.0 \pm .4$ & $17.1 \pm .8$ & $19.1 \pm .6$ & $16.2 \pm .4$ & $16.2 \pm .6$ & $7.8 \mathrm{NS}$ \\
\hline \multicolumn{7}{|l|}{$T_{\text {opt }}\left({ }^{\circ} \mathrm{C}\right):$} \\
\hline H. marinus & $25.0 \pm .5^{\mathrm{A}}$ & $25.0 \pm .01^{\mathrm{A}}$ & $24.7 \pm .5^{\mathrm{A}}$ & $24.7 \pm .3^{\mathrm{A}}$ & $21.1 \pm .5^{\mathrm{B}}$ & $61.6^{* * *}$ \\
\hline H. marionensis & $24.0 \pm .5^{\mathrm{A}}$ & $21.0 \pm .5^{\mathrm{B}}$ & $21.8 \pm .6^{\mathrm{B}}$ & $21.8 \pm .6^{\mathrm{B}}$ & $24.5 \pm .7^{\mathrm{A}}$ & $33.8^{\star \star *}$ \\
\hline H. belgicae & $23.3 \pm .6^{\mathrm{AB}}$ & $21.6 \pm .6^{\mathrm{AC}}$ & $25.00 \pm .40^{\mathrm{B}}$ & $20.8 \pm .9^{\mathrm{AC}}$ & $20.8 \pm .6^{\mathrm{C}}$ & $38.5^{\star \star \star}$ \\
\hline H. fulvus & $29.0 \pm .5^{\mathrm{A}}$ & $26.8 \pm .8^{\mathrm{AB}}$ & $25.6 \pm .4^{\mathrm{B}}$ & $24.5 \pm .8^{\mathrm{B}}$ & $28.3 \pm .8^{\mathrm{A}}$ & $32.1^{\star * \star}$ \\
\hline P. auberti & $24.0 \pm 1.1^{\mathrm{AB}}$ & $26.5 \pm 1.1^{\mathrm{AC}}$ & $25.3 \pm .3^{\mathrm{A}}$ & $22.9 \pm .6^{\mathrm{B}}$ & $27.8 \pm .7^{\mathrm{C}}$ & $24.0^{\star \star *}$ \\
\hline \multicolumn{7}{|l|}{$T_{\mathrm{br}}\left({ }^{\circ} \mathrm{C}\right):$} \\
\hline H. marinus & $17.0 \pm .5^{\mathrm{A}}$ & $13.6 \pm .4^{\mathrm{B}}$ & $13.0 \pm .6^{\mathrm{B}}$ & $13.0 \pm .3^{\mathrm{B}}$ & $11.2 \pm .8^{\mathrm{B}}$ & $61.2^{* * *}$ \\
\hline H. marionensis & $14.5 \pm .5^{\mathrm{A}}$ & $11.4 \pm .5^{\mathrm{BC}}$ & $13.6 \pm .6^{\mathrm{AB}}$ & $9.9 \pm .4^{\mathrm{C}}$ & $15.0 \pm .7^{\mathrm{A}}$ & $56.7^{\star \star \star *}$ \\
\hline H. belgicae & $13.5 \pm .5$ & $12.9 \pm .5$ & $12.2 \pm .4$ & $11.7 \pm .9$ & $13.0 \pm .5$ & $6.2 \mathrm{NS}$ \\
\hline H. fulvus & $17.3 \pm .5^{\mathrm{A}}$ & $15.2 \pm 1.0^{\mathrm{AB}}$ & $14.9 \pm .7^{\mathrm{AB}}$ & $14.3 \pm .8^{\mathrm{B}}$ & $18.6 \pm 1.1^{\mathrm{A}}$ & $18.9^{* * *}$ \\
\hline P. auberti & $15.2 \pm .8^{\mathrm{AB}}$ & $18.5 \pm .9^{\mathrm{C}}$ & $14.5 \pm .6^{\mathrm{AB}}$ & $12.7 \pm .6^{\mathrm{B}}$ & $16.5 \pm .5^{\mathrm{AC}}$ & $42.1^{\star \star \star}$ \\
\hline
\end{tabular}

Note: The $\chi^{2}$ values are the outcome of generalized linear models (see text for details), and different letters indicate significant differences between treatments based on $95 \%$ confidence limits. NS = not significant. Using García's (2004) false-discovery-rate criterion resulted in no changes to the significance values.

** $P<.01$.

$* * * P<.001$.

of the hypotheses. In the terrestrial species, Halozetes fulvus and Podacarus auberti, the hypothesis of no plasticity could not be rejected (table 4). In H. marinus, the deleterious acclimation hypothesis was supported, owing to a decline in performance at an acclimation temperature of $15^{\circ} \mathrm{C}$, as might be expected for a fully marine species living at constantly low temperatures. By contrast, in Halozetes marionensis, evidence for compensation and beneficial acclimation was found, whereas in Halozetes belgicae, the colder-is-better hypothesis was supported, though with some indication of inverse acclimation. The inverse acclimation effect was almost certainly due to the high value of $T_{\text {opt }}$ after the $5^{\circ} \mathrm{C}$ acclimation, an occurrence not repeated at $0^{\circ} \mathrm{C}$ (table 3$)$.

\section{Discussion}

Explicit consideration of the predictions of each of the acclimation hypotheses has demonstrated that performance curves can show a wide range of responses to acclimation (see also Huey et al. 1999). Moreover, graphical representation of the alternative hypotheses has also shown that compensation, or conservation of rate in the face of a temperature change (Hazel and Prosser 1974; Chown and Gaston 1999; Clarke 2003), is a special instance of the beneficial acclimation hypothesis. While such compensation has regularly been assumed to be adaptive (see dis- cussion in Huey and Berrigan 1996; Chown and Gaston 1999; Clarke 2003), appreciation of the fact that compensation can readily be included under the broad rubric of beneficial acclimation is less common. Recognition thereof could go some way toward resolving the theoretical and empirical controversy regarding whole-organismal metabolic rate compensation that has been a feature of the physiological literature for some time (Clarke 1993, 2003; Chown and Gaston 1999; Addo-Bediako et al. 2002; Hochachka and Somero 2002; Chown et al. 2003; Hodkinson 2003; Guderley 2004; see also Huey and Berrigan 1996).

In this study, a weak effect of beneficial acclimation and, in this case, compensation was found in one of the more marine species, Halozetes marionensis. Such an outcome is in keeping with the expectation from the majority of the literature on acclimation within life stages (Prosser 1986; Hochachka and Somero 2002; Wilson and Franklin 2002b; Woods and Harrison 2002) and with theoretical predictions regarding adaptive phenotypic plasticity (Van Tienderen 1997; Berrigan and Scheiner 2004). Likewise, compensation can be explained by the predictably low temperatures of the lower-shore/marine habitats occupied by this species (Mercer et al. 2000; table 1) and the likely absence of opportunities to make use of frequent periods of high temperature when activity can be maximized for mate finding, feeding, reproduction, and growth (Crafford et al. 1986; Convey 1994, 1996; Gotthard and Nylin 1995; 
Table 4: Summarized outcomes of the ordered-factor ANOVA with single-degree-of-freedom orthogonal polynomial contrasts for the effects of acclimation on optimum temperature $\left(T_{\text {opt }}\right)$, maximum rate of performance $\left(u_{\max }\right)$, and performance breadth $\left(T_{\mathrm{br}}\right)$

\begin{tabular}{lcclcc}
\hline Species & $T_{\mathrm{opt}}$ & $u_{\max }$ & Hypothesis & $T_{\mathrm{br}}$ & Hypothesis for $T_{\mathrm{br}}$ \\
\hline Halozetes marinus & $\mathrm{L}^{-}, \mathrm{Q}^{-}$ & $\mathrm{L}^{-}, \mathrm{Q}^{-}$ & $\mathrm{DAH}$ & $\mathrm{L}^{-}, \mathrm{Q}^{-}$ & \\
Halozetes marionensis & $\mathrm{L}^{+}$ & $\mathrm{NS}$ & $\mathrm{COMP} / \mathrm{BAH}$ & $\mathrm{L}^{+}, \mathrm{Q}^{+}$ & \\
Halozetes belgicae & $\mathrm{L}^{-}$ & $\mathrm{L}^{-}$ & $\mathrm{CIB}$ with IAH & $\mathrm{NS}$ & $\mathrm{NP}$ \\
Halozetes fulvus & $\mathrm{NS}$ & $\mathrm{NS}$ & $\mathrm{NP}$ & $\mathrm{NS}$ & $\mathrm{NP}$ \\
Podacarus auberti & $\mathrm{NS}$ & $\mathrm{NS}$ & $\mathrm{NP}$ & $\mathrm{L}^{-}, \mathrm{Q}^{+}$ & \\
\hline
\end{tabular}

Note: The hypothesis supported in the case of $T_{\mathrm{br}}$ is also indicated. $\mathrm{L}^{+}=$positive linear, $\mathrm{L}^{-}=$negative linear, $\mathrm{Q}^{+}=$positive quadratic, $\mathrm{Q}^{-}=$negative quadratic, $\mathrm{NS}=$ not significant. The combined effects on $T_{\mathrm{opt}}$ and $u_{\max }$ indicate the acclimation hypothesis that is supported. DAH $=$ deleterious acclimation, COMP/BAH = compensation and beneficial acclimation, $\mathrm{NP}=$ no plasticity, $\mathrm{CIB}$ with IAH $=$ colder is better and inverse acclimation. The analytical outcomes are given in full in appendix B in the online edition of the American Naturalist.

Chown 1997; Gotthard et al. 2000; Addo-Bediako et al. 2002). However, what is noteworthy is that these expectations were realized in a single species only. The other species departed significantly from them.

That the most marine of the species, Halozetes marinus, showed evidence of deleterious acclimation is also not unexpected, given the very narrow range of temperatures that this species is likely to encounter $\left(2^{\circ}-8^{\circ} \mathrm{C}\right.$; see Mélice et al. 2003; table 1). Indeed, it was clear that the $15^{\circ} \mathrm{C}$ acclimation temperature led to a substantial decline in the trait values relative to those found at the other acclimation temperatures, including the field-fresh treatment. Thus, the highest-temperature acclimation appeared to be deleterious, depressing overall performance, as has been implied for long-term acclimation treatments of other species (Woods and Harrison 2002). Unfortunately, independent assessments of stress for each treatment, such as the extent of upregulation of stress proteins (Feder and Hofmann 1999) or other thermal protectants (e.g., sorbitol; Salvucci 2000), were not undertaken, and therefore it could not be determined with certainty that the higher temperatures really were detrimental.

If the $15^{\circ} \mathrm{C}$ acclimation temperature is ignored, it appears that performance is generally better at lower temperatures in $H$. marinus, providing evidence in favor of the colder-is-better hypothesis (table 3). Support for this hypothesis was also found in the upper-shore species, Halozetes belgicae. Therefore, in the three species typical of the upper shoreline or marine habitats at Marion Island (see Mercer et al. 2000), some form of acclimation response was the norm. Moreover, these responses make sense from the perspective of the predictable, constantly low temperatures of the marine zone (although we acknowledge that $H$. belgicae is also common in upper-shore areas). Reasonably strong acclimation responses are expected in predictably varying environments (Scheiner 1993; Tufto 2000; Hazel et al. 2004), although stenothermal habitats are likely to reduce the scope of these responses
(Pörtner et al. 2000; Ghalambor et al. 2006). Here, significant though reasonably weak acclimation responses were found, in keeping with both theoretical predictions and empirical findings from elsewhere.

By contrast, in the terrestrial species, Halozetes fulvus and Podacarus auberti, no evidence was found for the BAH or for compensation, nor was evidence found to support the CIB or HIB hypotheses. Rather, in each of these species, the performance curves were similar irrespective of acclimation temperature. Therefore, the only plausible alternative is the hypothesis of no phenotypic plasticity. Whether such an absence of phenotypic plasticity can be considered adaptive is not clear. Several theoretical investigations have demonstrated that if environmental cues are misleading, plasticity will not be favored (Lively 1986; Moran 1992; Kingsolver and Huey 1998; de Jong 1999; Sultan and Spencer 2002; Berrigan and Scheiner 2004), and Tufto (2000) demonstrated that if unreliable cues are associated with environmental variability in general, they are apt to limit the evolution of plasticity. Arguably, environmental unpredictability, rather than variability per se, is prone to making cues even more misleading (Levins 1968; Kingsolver and Huey 1998). It is in temporally varying circumstances such as these that bias of the phenotype toward some global optimum would be most beneficial (Tufto 2000).

Terrestrial temperatures at Marion Island certainly span a smaller range than those at many other sites, and, in this sense, the climate of the island is considered one of the least variable globally (Gremmen 1981). However, what is perhaps of more consequence is that the variability in temperature is quite unpredictable. Low and high temperatures can be encountered at virtually any time of the year, and cold snaps in summer and relatively warm days in winter are common (Schulze 1971). A comparison of temporal autocorrelation of microclimate temperatures at sea level for Marion Island and for Lambert's Bay, on the southwest coast of South Africa, readily illustrates the 


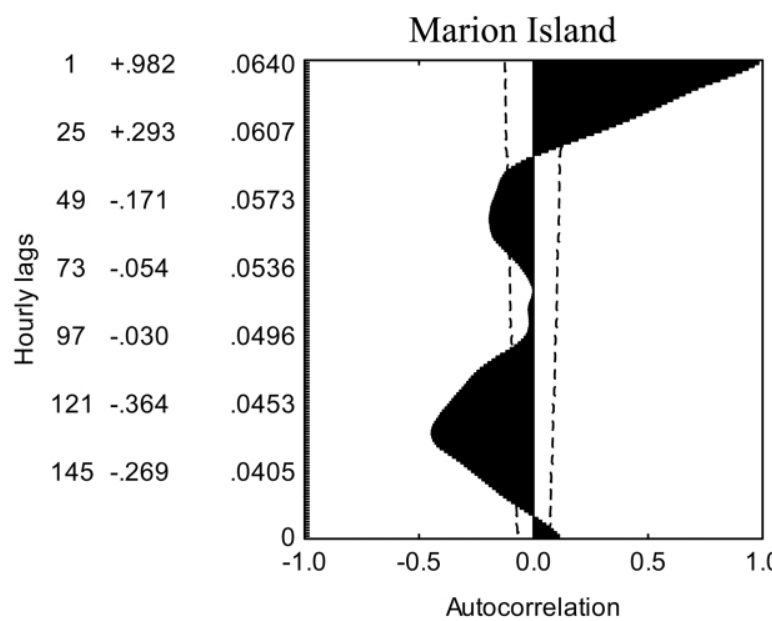

August 2002

$$
\begin{aligned}
& 1+.978 \\
& 25+.442 \\
& \begin{array}{lll}
49 & -.130
\end{array} \\
& \begin{array}{lll}
\text { 욘 } & & \\
\text { [ } & 73 & -.288
\end{array} \\
& \text { 온 } 97+.006 \\
& 121+.40 \\
& 145+.403
\end{aligned}
$$

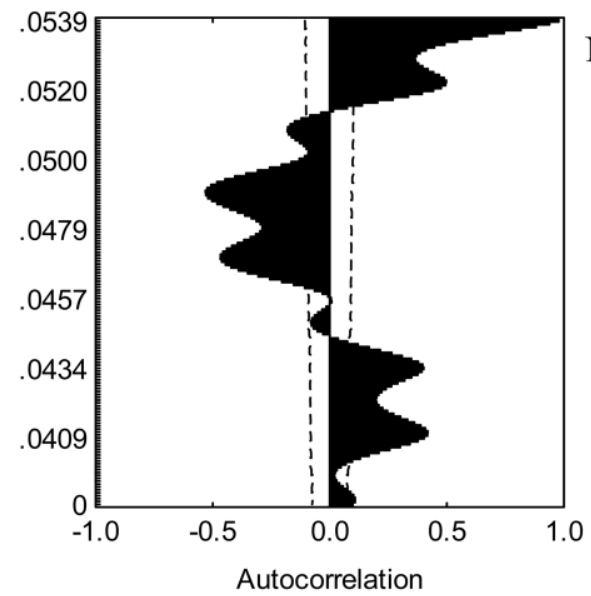

$$
\begin{aligned}
& 1+.977 \\
& 25-.086 \\
& \begin{array}{ll}
49 & -.051
\end{array}
\end{aligned}
$$

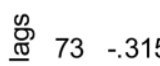

$$
\begin{aligned}
& \begin{array}{lll}
\text { 촌 } & 97 & -.090
\end{array} \\
& 121+.225 \\
& 145+.200
\end{aligned}
$$

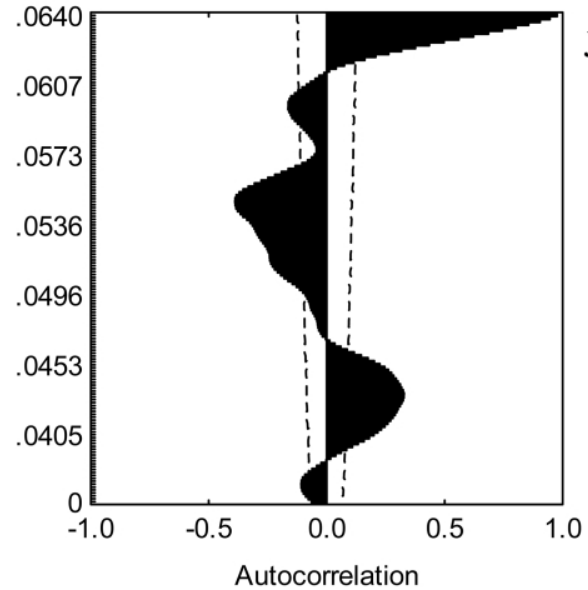

November 2002

Figure 3: Autocorrelation plots for hourly microclimate temperatures recorded on Marion Island during August 2002, November 2002, and June 2003. The dashed lines on each figure represent the $95 \%$ confidence intervals, while the values reported to the right of the lags on the $Y$-axis are the autocorrelation coefficients and their standard errors. 


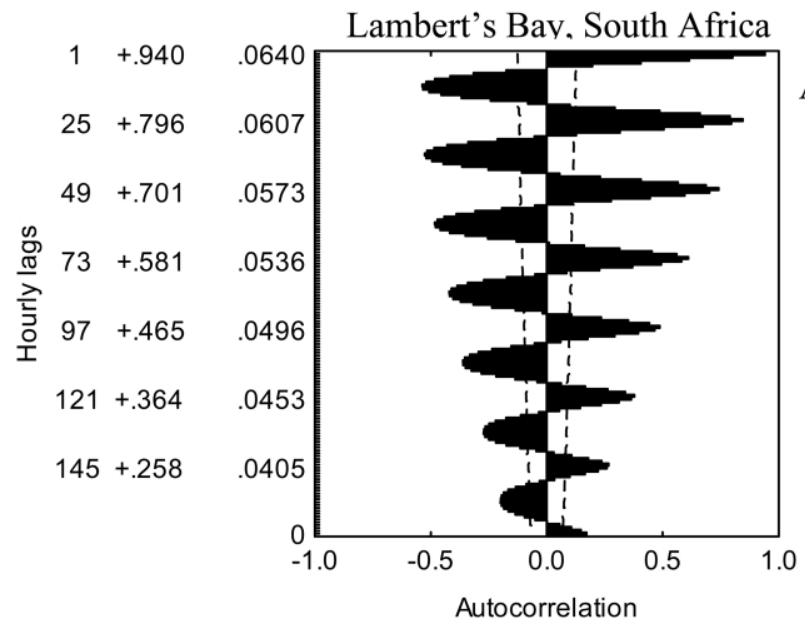

August 2002
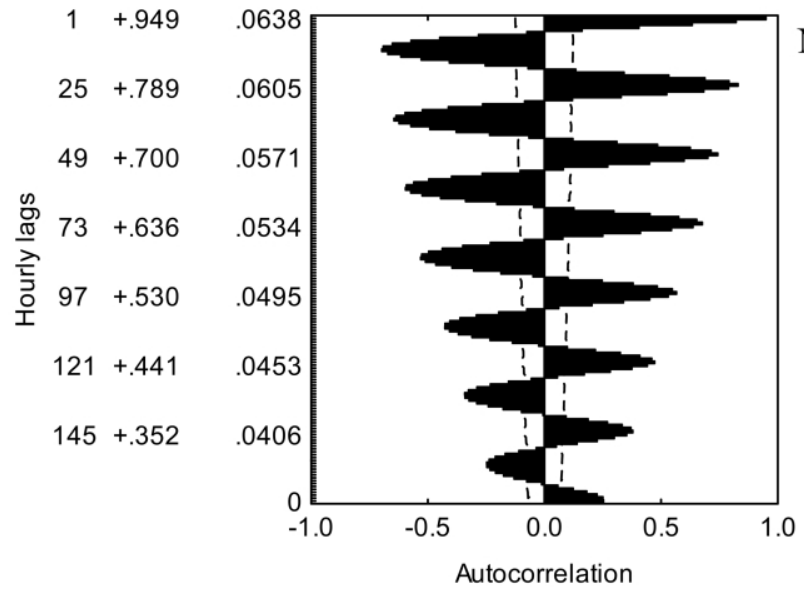

November 2002

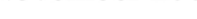

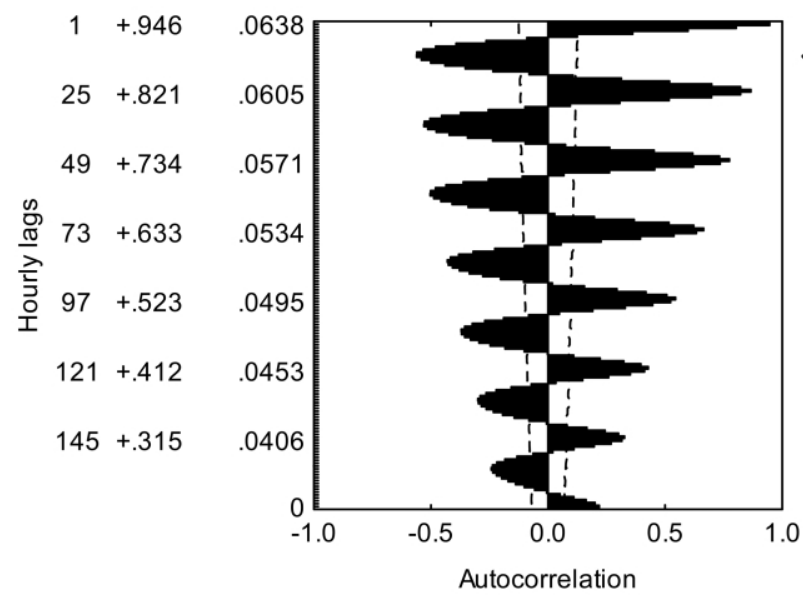

June 2003

Figure 4: Autocorrelation plots for hourly microclimate temperatures recorded at Lambert's Bay, South Africa, during August 2002, November 2002, and June 2003. The dashed lines on each figure represent the $95 \%$ confidence intervals, while the values reported to the right of the lags on the $Y$-axis are the autocorrelation coefficients and their standard errors. 
point. At both sites, microhabitat temperatures just below the soil surface in unshaded sites have been recorded hourly since June 2002 (and recordings are ongoing) using Thermocron iButtons (Dallas Semiconductors, Model DS1920), which have a resolution of $0.5^{\circ} \mathrm{C}$. For the purposes of this comparison, the first 10 days $(240 \mathrm{~h})$ of data from August 2002, November 2002, and June 2003 were subjected to temporal autocorrelation analysis, and the autocorrelation values for the hourly lags for the first 168 $\mathrm{h}$ (7 days) were calculated and plotted. These plots indicate that at Marion Island, current temperatures provide an indication of future temperatures for a day and a half at best (fig. 3). Thereafter, temperatures are significantly negatively autocorrelated, and the pattern of autocorrelation becomes irregular with increasing time from the time of interest. By contrast, daily temperatures are perfectly predictable at Lambert's Bay for a full week. Every $24 \mathrm{~h}$, temperatures are strongly correlated with those $24 \mathrm{~h}$ earlier (fig. 4), and by day 7 the autocorrelation has still not decayed to nonsignificant values. These patterns are typical for other months of the year at the two sites and support previous macroclimatological findings that weather conditions change in a matter of hours on the island (Schulze 1971).

Unpredictable variation in temperature on Marion Island could therefore have led to an adaptive response in the terrestrial mites in which a global optimum, with little phenotypic plasticity, is fixed (Tufto 2000). That several arthropod species here and elsewhere in the region show physiological responses that are typical of an unpredictable environment (Sinclair and Chown 2003; Sinclair et al. 2003) lends support to the idea of an adaptive absence of plasticity. Moreover, this general pattern of plasticity in marine but not terrestrial species has also been found in two other traits, supercooling point and lower lethal temperature, in these species, although $H$. belgicae showed little plasticity (Deere et al. 2006).

Nonetheless, several conditions would have to be satisfied to show that the lack of plasticity in the nonmarine mite species is indeed adaptive, including demonstration of consistent variation among individuals, a genetic basis for the traits, and a relationship between variation in locomotor performance and fitness. For plasticity of locomotor performance, these conditions are all controversial (Heinrich and Bartholomew 1979; Via et al. 1995; Gilchrist 1996; Scott et al. 1997; Hoffmann and Hewa-Kapuge 2000; Gibert et al. 2001; Angilletta et al. 2002; Sarkar 2004), and data are not available for the mite species in question. Thus, the question of an adaptive absence of phenotypic plasticity in the mite species is difficult to resolve. Demonstration of adaptive phenotypic plasticity in the other three species would be complicated for similar reasons.

An alternative explanation for both the absence of plas- ticity in the fully terrestrial species and the weak plasticity in the marine and upper-shore ones might be that the lack of plasticity or weak presence thereof is a plesiomorphic characteristic of an ancient Gondwanan group (Marshall and Pugh 1996; Marshall and Coetzee 2000; Procheş and Marshall 2001). That both $u_{\max }$ and $T_{\mathrm{opt}}$ in these species are similar to those of the distantly related continental Antarctic mite species Maudheimia petronia (Marshall et al. 1995) suggests that this is a plausible alternative, as does the mismatch between optimum temperatures and likely habitat temperatures, which has been noted for other species (Hertz et al. 1983; Abushama and Al-Salameen 1989; Ward and Seely 1996; Bennett 2004). However, only a comprehensive investigation of the above conditions would allow the adaptive and constraint hypotheses to be distinguished.

In conclusion, this study has rejected the beneficial acclimation hypothesis for two and perhaps three labile traits within a given life stage for four of five mite species. It therefore lends support to previous arguments (summarized in Huey and Berrigan 1996) that the beneficial acclimation hypothesis requires more cautious scrutiny than it has received in the past. Moreover, this work also shows that unpredictability is an important feature of the environment that is likely to shape the nature and extent of phenotypic plasticity. It also draws attention to differences in predictability that exist between marine and terrestrial environments (see also Vasseur and Yodzis 2004) and the consequences these differences might hold for species physiological responses.

\section{Acknowledgments}

We thank D. Marshall for assistance in the field, J. Terblanche and M. McGeoch for comments on an earlier draft of the manuscript, E. Gray for statistical advice, and the South African Weather Services for sea surface temperature data. We are especially grateful to R. Huey for a midcourse correction to the work that emphasized the significance of unpredictability, to G. Gilchrist for his patient and helpful assistance with the orthogonal polynomial contrasts calculated in $\mathrm{R}$, and to three anonymous reviewers for their insightful comments on previous versions. This study was partially supported by the United States Agency for International Development Capacity Building Program for Climate Change Research and the South African Department of Environmental Affairs and Tourism.

\section{Literature Cited}

Abushama, F. T., and M. A. Al-Salameen. 1989. Temperature reactions of desert tenebrionid beetles from Kuwait. Journal of Arid Environments 16:293-304.

Addo-Bediako, A., S. L. Chown, and K. J. Gaston. 2002. Metabolic 
cold adaptation in insects: a large-scale perspective. Functional Ecology 16:332-338.

Agrawal, A. A. 2001. Phenotypic plasticity in the interaction and evolution of species. Science 294:321-326.

Angilletta, M. J., Jr., P. H. Niewiarowski, and C. A. Navas. 2002. The evolution of thermal physiology in ectotherms. Journal of Thermal Biology 27:249-268.

Angilletta, M. J., Jr., R. S. Wilson, C. A. Navas, and R. S. James. 2003. Tradeoffs and the evolution of thermal reaction norms. Trends in Ecology \& Evolution 18:234-240.

Barendse, J., R. D. Mercer, D. J. Marshall, and S. L. Chown. 2002. Habitat specificity of mites on sub-Antarctic Marion Island. Environmental Entomology 31:612-625.

Bennett, A. B. 2004. Thermoregulation in African chameleons. International Congress Series 1275:234-241.

Bennett, A. F., and R. E. Lenski. 1997. Evolutionary adaptation to temperature. VI. Phenotypic acclimation and its evolution in Escherichia coli. Evolution. 51:36-44.

Berrigan, D., and S. M. Scheiner. 2004. Modeling the evolution of phenotypic plasticity. Pages 82-97 in T. J. DeWitt and S. M. Scheiner, eds. Phenotypic plasticity: functional and conceptual approaches. Oxford University Press, Oxford.

Blake, B. E. 1996. Microclimate and prediction of photosynthesis at Marion Island. MSc thesis. University of the Free State, Bloemfontein, South Africa.

Carrière, Y., and G. Boivin. 1997. Evolution of thermal sensitivity of parasitization capacity in egg parasitoids. Evolution 51:2028-2032.

Chown, S. L. 1997. Thermal sensitivity of oxygen uptake of Diptera from sub-Antarctic South Georgia and Marion Island. Polar Biology 17:81-86.

Chown, S. L., and J. E. Crafford. 1992. Microhabitat temperatures at Marion Island $\left(46^{\circ} 54^{\prime} \mathrm{S} 37^{\circ} 45^{\prime} \mathrm{E}\right)$. South African Journal of Antarctic Research 22:51-58.

Chown, S. L., and K. J. Gaston. 1999. Exploring links between physiology and ecology at macro-scales: the role of respiratory metabolism in insects. Biological Reviews 74:87-120.

Chown, S. L., and S. W. Nicolson. 2004. Insect physiological ecology: mechanisms and patterns. Oxford University Press, Oxford.

Chown, S. L., A. Addo-Bediako, and K. J. Gaston. 2003. Physiological diversity: listening to the large-scale signal. Functional Ecology 17: 562-572.

Clarke, A. 1993. Seasonal acclimatization and latitudinal compensation in metabolism: do they exist? Functional Ecology 7:139149.

2003. Costs and consequences of evolutionary temperature adaptation. Trends in Ecology \& Evolution 18:573-581.

Cohet, Y., and J. David. 1977. Control of adult reproductive potential by preimaginal thermal conditions: a study in Drosophila melanogaster. Oecologia (Berlin) 36:295-306.

Convey, P. 1994. Growth and survival strategy of the Antarctic mite Alaskozetes antarcticus. Ecography 17:97-107.

- 1996. The influence of environmental characteristics on life history attributes of Antarctic terrestrial biota. Biological Reviews 71:191-225.

Crafford, J. E., C. H. Scholtz, and S. L. Chown. 1986. The insects of sub-Antarctic Marion and Prince Edward islands, with a bibliography of entomology of the Kerguelen biogeographical province. South African Journal of Antarctic Research 16:42-84.

David, J. R., P. Gibert, E. Gravot, G. Petavy, J. Morin, D. Karan, and B. Moreteau. 1997. Phenotypic plasticity and developmental tem- perature in Drosophila: analysis and significance of reaction norms of morphometrical traits. Journal of Thermal Biology 22:441-451.

Deere, J. A., B. J. Sinclair, D. J. Marshall, and S. L. Chown. 2006. Phenotypic plasticity of thermal tolerances in five oribatid mite species from sub-Antarctic Marion Island. Journal of Insect Physiology 52:693-700.

de Jong, G. 1999. Unpredictable selection in a structured population leads to local genetic differentiation in evolved reaction norms. Journal of Evolutionary Biology 12:839-851.

Falconer, D. S., and T. F. C. Mackay. 1996. Introduction to quantitative genetics. Prentice Hall, London.

Feder, M. E., and G. E. Hofmann. 1999. Heat-shock proteins, molecular chaperones, and the stress response: evolutionary and ecological physiology. Annual Review of Physiology 61:243-282.

Fischer, K., E. Eenhoorn, A. N. M. Bot, P. M. Brakefield, and B. J. Zwaan. 2003. Cooler butterflies lay larger eggs: developmental plasticity versus acclimation. Proceedings of the Royal Society B: Biological Sciences 270:2051-2056.

García, L. V. 2004. Escaping the Bonferroni iron claw in ecological studies. Oikos 105:657-663.

Ghalambor, C. K., R. B. Huey, P. R. Martin, J. J. Tewksbury, and G. Wang. 2006. Are mountain passes higher in the tropics? Janzen's hypothesis revisited. Integrative and Comparative Biology 46:517.

Gibert, P., R. B. Huey, and G. W. Gilchrist. 2001. Locomotor performance of Drosophila melanogaster: interactions among developmental and adult temperatures, age, and geography. Evolution 55:205-209.

Gilchrist, G. W. 1996. A quantitative genetic analysis of thermal sensitivity in the locomotor performance curve of Aphidius ervi. Evolution 50:1560-1572.

Gilchrist, G. W., and R. B. Huey. 2001. Parental and developmental temperature effects on the thermal dependence of fitness in Drosophila melanogaster. Evolution 55:209-214.

- 2004. Plastic and genetic variation as a function of temperature within and among parallel clines in Drosophila subobscura. Integrative and Comparative Biology 44:461-470.

Gotthard, K., and S. Nylin. 1995. Adaptive plasticity and plasticity as an adaptation: a selective review of plasticity in animal morphology and life history. Oikos 74:3-17.

Gotthard, K., S. Nylin, and C. Wiklund. 2000. Individual state controls temperature dependence in a butterfly (Lassiommata maera). Proceedings of the Royal Society B: Biological Sciences 267:589593.

Gremmen, N. J. M. 1981. The vegetation of the sub-Antarctic islands Marion and Prince Edward. Junk, The Hague.

Guderley, H. 2004. Metabolic responses to low temperature in fish muscle. Biological Reviews 79:409-427.

Hazel, J. R., and C. L. Prosser. 1974. Molecular mechanisms of temperature compensation in poikilotherms. Physiological Reviews 54: 620-677.

Hazel, W., R. Smock, and C. M. Lively. 2004. The ecological genetics of conditional strategists. American Naturalist 163:888-900.

Heinrich, B., and G. A. Bartholomew. 1979. Roles of endothermy and size in inter- and intraspecific competition for elephant dung in an African dung beetle, Scarabaeus laevistriatus. Physiological Zoology 52:484-496.

Hertz, P. E., R. B. Huey, and E. Nevo. 1983. Homage to Santa Anita: thermal sensitivity of sprint speed in agamid lizards. Evolution 37: $1075-1084$. 
Hochachka, P. W., and G. N. Somero. 2002. Biochemical adaptation: mechanism and process in physiological evolution. Oxford University Press, Oxford.

Hodkinson, I. D. 2003. Metabolic cold adaptation in arthropods: a smaller-scale perspective. Functional Ecology 17:562-567.

Hoffmann, A. A. 1995. Acclimation: increasing survival at a cost. Trends in Ecology \& Evolution 10:1-2.

Hoffmann, A. A., and S. Hewa-Kapuge. 2000. Acclimation for heat resistance in Trichogramma nr. brassicae: can it occur without costs? Functional Ecology 14:55-60.

Hoffmann, A. A., and M. Watson. 1993. Geographical variation in the acclimation responses of Drosophila to temperature extremes. American Naturalist 142(suppl.):S93-S113.

Huey, R. B., and D. Berrigan. 1996. Testing evolutionary hypotheses of acclimation. Pages 205-237 in I. A. Johnston and A. F. Bennett, eds. Animals and temperature: phenotypic and evolutionary adaptation. Cambridge University Press, Cambridge.

Huey, R. B., and P. E. Hertz. 1984. Is a jack-of-all-temperatures a master of none? Evolution 38:441-444.

Huey, R. B., and J. G. Kingsolver. 1993. Evolution of resistance to high temperature in ectotherms. American Naturalist 142(suppl.): S1-S46.

Huey, R. B., and R. D. Stevenson. 1979. Integrating thermal physiology and ecology of ectotherms: a discussion of approaches. American Zoologist 19:357-366.

Huey, R. B., D. Berrigan, G. W. Gilchrist, and J. C. Herron. 1999. Testing the adaptive significance of acclimation: a strong inference approach. American Zoologist 39:323-336.

Kingsolver, J. G., and R. B. Huey. 1998. Evolutionary analyses of morphological and physiological plasticity in thermally variable environments. American Zoologist 38:545-570.

Klok, C. J., and S. L. Chown. 2003. Resistance to temperature extremes in sub-Antarctic weevils: interspecific variation, population differentiation and acclimation. Biological Journal of the Linnean Society 78:401-414.

Leroi, A. M., A. F. Bennett, and R. E. Lenski. 1994. Temperature acclimation and competitive fitness: an experimental test of the beneficial acclimation assumption. Proceedings of the National Academy of Sciences of the USA 91:1917-1921.

Lessells, C. M., and P. T. Boag. 1987. Unrepeatable repeatabilities: a common mistake. Auk 104:116-121.

Levins, R. 1968. Evolution in changing environments. Princeton University Press, Princeton, NJ.

Lively, C. M. 1986. Canalization versus developmental conversion in a spatially variable environment. American Naturalist 128:561572 .

Loeschcke, V., and A. A. Hoffmann. 2002. The detrimental acclimation hypothesis. Trends in Ecology \& Evolution 17:407-408.

Marshall, D. J., and S. L. Chown. 1995. Temperature effects on locomotor activity rates of sub-Antarctic oribatid mites. Polar Biology 15:47-49.

Marshall, D. J., and L. Coetzee. 2000. Historical biogeography and ecology of a continental Antarctic mite genus, Maudheimia (Acari, Oribatida): evidence for a Gondwanan origin and Plio-Pleistocene speciation. Zoological Journal of the Linnean Society 129:111-128.

Marshall, D. J., and P. J. A. Pugh. 1996. Origin of the inland Acari of continental Antarctica, with particular reference to Dronning Maud Land. Zoological Journal of the Linnean Society 118:101118.

Marshall, D. J., I. P. Newton, and J. E. Crafford. 1995. Habitat tem- perature and potential locomotor activity of the continental Antarctic mite, Maudheimia petronia Wallwork (Acari: Oribatei). Polar Biology 15:41-46.

Mélice, J.-L., J. R. E. Lutjeharms, M. Rouault, and I. J. Ansorge. 2003. Sea-surface temperatures at the sub-Antarctic islands Marion and Gough during the past 50 years. South African Journal of Science 99:363-366.

Mercer, R. D., S. L. Chown, and D. J. Marshall. 2000. Mite and insect zonation on a Marion Island rocky shore: a quantitative approach. Polar Biology 23:775-784.

Mercer, R. D., A. G. A. Gabriel, J. Barendse, D. J. Marshall, and S. L. Chown. 2001. Invertebrate body sizes from Marion Island. Antarctic Science 13:135-143.

Moran, N. A. 1992. The evolutionary maintenance of alternative phenotypes. American Naturalist 139:971-989.

Pörtner, H. O., P. L. M. van Dijk, I. Hardewig, and A. Sommer. 2000. Levels of metabolic cold adaptation: tradeoffs in eurythermal and stenothermal ectotherms. Pages 109-122 in W. Davison, C. Howard-Williams, and P. A. Broady, eds. Antarctic ecosystems: models for wider ecological understanding. New Zealand Natural Sciences, Christchurch.

Procheş, S., and D. J. Marshall. 2001. Global distribution patterns of non-halacarid intertidal marine mites: implications for their origin in marine habitats. Journal of Biogeography 28:47-58.

Prosser, C. L. 1986. Adaptational biology: molecules to organisms. Wiley, New York.

Salvucci, M. E. 2000. Sorbitol accumulation in whiteflies: evidence for a role in protecting proteins during heat stress. Journal of Thermal Biology 25:353-361.

Sarkar, S. 2004. From the reaktionsnorm to the evolution of adaptive plasticity: a historical sketch, 1909-1999. Pages 10-30 in T. J. DeWitt and S. M. Scheiner, eds. Phenotypic plasticity: functional and conceptual approaches. Oxford University Press, Oxford.

Scheiner, S. M. 1993. Genetics and evolution of phenotypic plasticity. Annual Review of Ecology and Systematics 24:35-68.

Schulze, B. R. 1971. The climate of Marion Island. Pages 16-31 in E. M. van Zinderen Bakker, J. M. Winterbottom, and R. A. Dyer, eds. Marion and Prince Edward islands: report on the South African biological and geological expedition 1965-1966. Balkema, Cape Town.

Scott, M., D. Berrigan, and A. A. Hoffmann. 1997. Costs and benefits of acclimation to elevated temperature in Trichogramma carverae. Entomologia Experimentalis et Applicata 85:211-219.

Sibly, R. M., L. Winokur, and R. H. Smith. 1997. Interpopulation variation in phenotypic plasticity in the speckled wood butterfly, Pararge aegeria. Oikos 78:323-330.

Sinclair, B. J., and S. L. Chown. 2003. Rapid response to high temperature and desiccation but not to low temperature in the freeze tolerant sub-Antarctic caterpillar Pringleophaga marioni (Lepidoptera, Tineidae). Journal of Insect Physiology 49:45-52.

Sinclair, B. J., A. Addo-Bediako, and S. L. Chown. 2003. Climatic variability and the evolution of insect freeze tolerance. Biological Reviews 78:181-195.

Smith, V. R. 2002. Climate change in the sub-Antarctic: an illustration from Marion Island. Climatic Change 52:345-357.

Spicer, J. I., and K. J. Gaston. 1999. Physiological diversity and its ecological implications. Blackwell Science, Oxford.

Stevenson, R. D. 1985. The relative importance of behavioral and physiological adjustments controlling body temperature in terrestrial ectotherms. American Naturalist 126:362-386. 
Sultan, S. E., and H. G. Spencer. 2002. Metapopulation structure favors plasticity over local adaptation. American Naturalist 160: 271-283.

Terblanche, J. S., C. J. Klok, E. S. Krafsur, and S. L. Chown. 2006. Phenotypic plasticity and geographic variation in thermal tolerance and water loss of the tsetse fly Glossina pallidipes (Diptera: Glossinidae): implications for distribution modelling. American Journal of Tropical Medicine and Hygiene 74:786-794.

Tufto, J. 2000. The evolution of plasticity and nonplastic spatial and temporal adaptations in the presence of imperfect environmental cues. American Naturalist 156:121-130.

Van Tienderen, P. H. 1997. Generalists, specialists, and the evolution of phenotypic plasticity in sympatric populations of distinct species. Evolution 51:1372-1380.

Vasseur, D. A., and P. Yodzis. 2004. The color of environmental noise. Ecology 85:1146-1152.

Via, S., R. Gomulkiewicz, S. M. Scheiner, C. D. Schlichting, and P. H. Van Tienderen. 1995. Adaptive phenotypic plasticity: consensus and controversy. Trends in Ecology \& Evolution 10:212-217.

Ward, D., and M. K. Seely. 1996. Adaptation and constraint in the evolution of the physiology and behavior of the Namib Desert tenebrionid beetle genus Onymacris. Evolution 50:1231-1240.

Willmer, P., G. Stone, and I. A. Johnston. 1999. Environmental physiology of animals. Blackwell Science, Oxford.
Wilson, R. S., and C. E. Franklin. 2002a. The detrimental acclimation hypothesis. Trends in Ecology \& Evolution 17:407-408.

. 2002b. Testing the beneficial acclimation hypothesis. Trends in Ecology \& Evolution 17:66-70.

Woods, H. A. 1999. Patterns and mechanisms of growth of fifthinstar Manduca sexta caterpillars following exposure to low- or high-protein food during early instars. Physiological and Biochemical Zoology 72:445-454.

Woods, H. A., and J. F. Harrison. 2001. The beneficial acclimation hypothesis versus acclimation of specific traits: physiological change in water-stressed Manduca sexta. Physiological and Biochemical Zoology 74:32-44.

- 2002. Interpreting rejections of the beneficial acclimation hypothesis: when is physiological plasticity adaptive? Evolution 56: 1863-1866.

Zamudio, K. R., R. B. Huey, and W. D. Crill. 1995. Bigger isn't always better: body size, developmental and parental temperature, and territorial success in Drosophila melanogaster. Animal Behaviour 49:671-677.

Zeilstra, I., and K. Fischer. 2005. Cold tolerance in relation to developmental and adult temperature in a butterfly. Physiological Entomology 30:92-95.

Associate Editor: George W. Gilchrist Editor: Jonathan B. Losos 